\title{
An Evaluation of Glucagon Injection Anxiety and Its Association with the Fear of Hypoglycemia among the Parents of Children with Type 1 Diabetes
}

\author{
(D) Serra Muradoğlu, (D) Gül Yeşiltepe Mutlu, (D) Tuğba Gökçe, (D) Ecem Can, (1) Şükrü Hatun \\ Koç University Faculty of Medicine, Department of Pediatric Endocrinology and Diabetes, Istanbul, Turkey
}

\begin{abstract}
What is already known on this topic?
Previous research has shown that parental anxiety and prior experiences of hypoglycemia can impair the management of diabetes and make parents more fearful about hypoglycemia. Research on parental attitudes and beliefs towards glucagon administration is lacking.
\end{abstract}

\section{What this study adds?}

The current study shows a positive association between parental fear of hypoglycemia and parental anxiety concerning glucagon administration. Practical training should be carried out to improve the self-confidence of caregivers.

\begin{abstract}
Objective: Hypoglycemia is a common acute complication of type 1 diabetes (T1D), which may cause seizure, loss of consciousness, and temporary motor or sensory impairment. Glucagon administration is an effective way of treating severe hypoglycemia, especially in a free-living setting. Nonetheless, families have difficulties in managing severe hypoglycemia due to their anxiety and challenges with current glucagon administration techniques. The aim of the current study was to explore the associations between parental fear of hypoglycemia (FoH) and their general anxiety level, and in particular, their attitudes towards and thoughts on glucagon administration. Methods: Parents of children with T1D completed questionnaires assessing background and clinical information, FoH, generalized anxiety disorder (GAD) and parental anxiety for glucagon administration (PAGA).

Results: Sixty-eight parents participated. Positive correlations were found between parental GAD-7 score and both FoH and the number of night-time blood glucose measurements and there was a negative correlation with the child's age. Parents mean self-evaluation score of their competence in glucagon administration was 6 (standard deviation \pm 2.9 ) on a scale of 0 to 10 . Unsurprisingly, this score was negatively correlated with the PAGA scores. There was no significant difference between children using continuous glucose monitoring system and self-monitoring of blood glucose in terms of parental FoH, anxiety and misconceptions about glucagon administration.

Conclusion: The results showed that parents of children with T1D had anxiety and fear connected with hypoglycemia and glucagon administration. Structured and practical training should be implemented to increase parents' self-confidence including annual refresher training for home glucagon administration.
\end{abstract}

Keywords: Hypoglycemia, glucagon, anxiety, diabetes mellitus type 1

\section{Introduction}

Hypoglycemia is a common complication in type 1 diabetes mellitus (T1D) treatment and refers to conditions where blood glucose levels are $\leq 70 \mathrm{mg} / \mathrm{dL}$ (1). The symptoms of hypoglycemia include tremors, sweating, palpitations, increased feeling of hunger, anxiety, nausea, headache, sleepiness, excessive fatigue, and attention difficulties. Hypoglycemia may also have more serious consequences, such as coma, seizure, and temporary motor or sensory
Address for Correspondence: Serra Muradoğlu MD, Koç University Faculty of Medicine, Department of Pediatric Endocrinology and Diabetes, İstanbul, Turkey

Phone: + 905446045544 E-mail: skupcuoglu@ku.edu.tr ORCID: orcid.org/0000-0002-7627-0862
Conflict of interest: None declared Received: 17.09.2020 Accepted: 02.01.2021 
impairment (2). The symptoms of hypoglycemia, which are acute, occasionally dramatic, and may be accompanied by convulsions, cause fear of hypoglycemia $(\mathrm{FoH})$ in families, especially at night (3). This fear is more evident in the families of young children ( $<6$ years) who are unable to recognize the symptoms of hypoglycemia quickly enough to counter it, often causing these families to spend the night without sleeping (4). The feelings of families, and especially the mothers, regarding hypoglycemia vary according to local cultures (5). Although coma due to severe hypoglycemia is very rare and the prevalence of hypoglycemia-related death is unclear, many families fear that they might find "their children dead in bed", even if their children have only had severe hypoglycemic convulsions once (1). This false notion may change their priorities in diabetes treatment. Although diabetes technologies, especially continuous glucose monitoring (CGM) systems with alarms, have played an important role in reducing the fears of families in recent years, it is still known that FoH could be a significant barrier to achieving improvement in glycemic targets (4).

Moreover, with regard to the treatment of severe hypoglycemia, for many years, the only available form of glucagon has involved preparation by injecting a diluent into the powdered drug (6). Recently launched intranasal glucagon and premixed glucagon are inaccessible to most people with T1D outside of the USA. The most commonly used glucagon form is administered with the injector perpendicular to the front side of the arm or leg. Studies show that families have difficulty in managing the process of severe hypoglycemia, especially when it is accompanied by impaired consciousness (7). Our experience has suggested that families tend to go to the hospital as a matter of urgency rather than using glucagon itself due to their anxieties involving glucagon administration. Consequently, this anxiety related to glucagon administration, in addition to the FoH may have reduced the observed rates of parental/ patient administered glucagon and consequently the value of glucagon. Given that it is assumed that caregivers can easily administer glucagon in the treatment of severe hypoglycaemia, parental concerns about this process may not have been taken into account sufficiently in standard diabetes education by healthcare professionals.

While previous research has shown that anxiety of the parent and prior experiences of hypoglycemia can impair the management of diabetes $(7,8)$, research on attitudes towards glucagon administration is lacking. The current study aimed to explore the associations between parental FoH and their general anxiety level, in particular, their attitudes towards and thoughts about glucagon administration.

\section{Methods}

\section{Study Sample}

The parents of children aged between 2 and 18 years who had been diagnosed with T1D at least six months previously and followed by our pediatric endocrinology department were invited to participate in the study. At the beginning of the survey, the informed consent was obtained from the participants. There was no ethical committee application for the current study. Nonetheless, the Koç University Ethics Committee has concluded that the research had not violated the bioethical principles. The relevant letter from the committee is included in the supplementary file.

\section{Measures}

All forms were sent in a format suitable for online completion by the participants.

The Demographic form consisted of information about the child's gender, date of birth, date of diagnosis of diabetes, frequency of daytime and nighttime glucose measurement, diabetes technology usage, frequency of hypoglycemia, and information related to glucagon usage, such as injection sites and deciding accurate doses. The last $\mathrm{HbA} 1 \mathrm{c}$ results of the children given in percentages were gathered from our hospital's laboratory data. The parents were also asked to rate their competence in glucagon administration on a scale of 0 to 10 points.

The Fear of Hypoglycemia Questionnaire-Parent Form was developed by Gonder-Frederick et al (8). The reliability and validity of the scale in Turkish was conducted by Şen Celasin et al (9). It measures parental FoH with a total of 25 items divided into 15 items for the anxiety subscale and 10 items for the behavior subscale. Increasing scores represent increasing severity of $\mathrm{FoH}$.

The Generalized Anxiety Disorder-7 Scale (GAD-7) was developed according to the Diagnostic and Statistical Manual of Mental Disorders-IV-TR criteria (10) and its Turkish validity and reliability were confirmed (11). It is a short, self-reported 7 -item scale evaluating GAD. Increasing scores represent the increasing severity of anxiety.

The Questionnaire Evaluating Parental Anxiety for Glucagon Administration (PAGA) is a 10-item questionnaire that aims to investigate parental misconceptions and perceptions of barriers to administration of glucagon. It is a 5-point Likert scale response eliciting how concerned they are about each statement. The questionnaire consists of statements including "the belief that the needle will hurt because of the length", "the belief that if I administer the glucagon, I will be too late to take him to the emergency room", "the 
belief that my child will not get better, even if I administer the glucagon". In many years of experience, our pediatric endocrinology team observed common misconceptions and barriers reported by families about glucagon usage. Due to the lack of any existing questionnaire regarding this matter, the questions were developed based on the clinical observations of the team. The internal consistency evaluated with Cronbach's alpha was found to be 0.89. Increasing scores represent increasing misconceptions about glucagon administration. The questionnaire is shown in Appendix 1.

\section{Statistical Analysis}

Analyses were conducted using Statistical Package for the Social Sciences version 23.0. (IBM Corp., Armonk, N.Y., USA). Descriptive statistics (means, standard deviations, frequencies, and percent) were used to summarize demographic and clinical variables. T-tests were used to assess the associations between categorical variables and continuous variables. The group differences were analyzed using Mann-Whitney $U$ test. Bivariate and partial correlations were used to determine the relation between continuous variables.

\section{Results}

A total of 153 parents of children aged between 2 and 18 years who had been diagnosed with T1D at least six months previously and followed by our pediatric endocrinology department were invited to participate in the study. Of these, 96 accepted, and 68 parents completed all of the surveys. The participation flow chart is shown in Figure 1. The mean age of the children was $9.5 \pm 4.1$ years and the mean diabetes duration was $2.9 \pm 2.2$ years. Of the participants' children, $14(21 \%)$ were on insulin infusion pump (IIP) therapy and all the pumps were Medtronic 640G. The rest of the participants were on multiple dose injection therapy (MDI). The descriptive information is shown in Table 1. The analysis of the survey data showed that the education levels of the participants were as follows: two $(2.9 \%)$ parents were primary school graduates, two (2.9\%) were secondary school graduates, 20 (29.4\%) of the

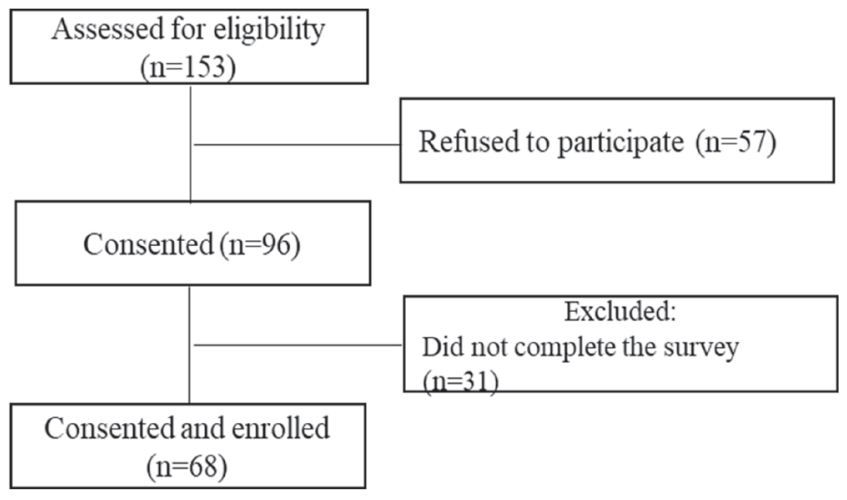

Figure 1. Study flow diagram

\begin{tabular}{|c|c|c|}
\hline$\%$ or mean \pm SD & & Range \\
\hline Sex (female \%) & 51.5 & \\
\hline Child's age (years) & $9.5 \pm 4.1$ & $2.7-17.5$ \\
\hline Diabetes duration (months) & $2.9 \pm 2.2$ & $0.5-9.6$ \\
\hline $\operatorname{HbA1c}(\%)$ & $7.6 \pm 1.4$ & $5.5-14$ \\
\hline Insulin regimen (pump \%) & 21 & \\
\hline CGM usage $(\%)$ & 57.4 & \\
\hline Number of the times blood glucose $<50 \mathrm{mg} / \mathrm{dL}$ in the past 3 months & $5 \pm 5.9$ & $0-20$ \\
\hline Glucagon administration or emergency room visit in the past 12 months & $0.1 \pm 0.5$ & $0-3$ \\
\hline Number of times experiencing unconsciousness/seizures ever & $0.3 \pm 0.6$ & $0-4$ \\
\hline \multicolumn{3}{|l|}{ Number of day-time glucose measurement } \\
\hline$<3$ times/day & 12 & \\
\hline 4-6 times/day & 35 & \\
\hline$\geq 7$ times/day & 53 & \\
\hline \multicolumn{3}{|l|}{ Number of night-time glucose measurement: } \\
\hline$<1$ time/week & 28 & \\
\hline 1 time/week & 12 & \\
\hline 2-4 times/week & 23 & \\
\hline$\geq 7$ times/week & 36 & \\
\hline
\end{tabular}

SD: standard deviation, CGM: continuous glucose monitoring 
parents were high school graduates, 36 (52.9\%) parents had university degrees and eight (11.8\%) had masters-degrees. Of the parents, 23 (34\%) were unemployed. Ninety-three percent of the parents $(n=63)$ stated that they were trained in glucagon administration and 13 reported administering glucagon to their child in a severe hypoglycemia emergency. Glucagon was available in 65 of the houses and 29 of the schools of the children. On average, the parents evaluated their competence in glucagon administration as $6 \pm 2.9$ out of 10 . Of the participants, $85 \%(n=58)$ reported that they would administer glucagon immediately if there was a loss of consciousness.

The mean GAD-7 score of the participants was $6.6 \pm 5.4(0$ $21)$. According to the cut off points in the GAD-7 (11), 30 (44.1\%) of the parents had no anxiety, 20 (29.4\%) of them had mild anxiety, 11 (16.2\%) of them had moderate levels of anxiety and 7 (10.3\%) of them had severe anxiety.

A positive correlation was found between the $\mathrm{FoH}$ and the GAD-7 scores of the parents. This relationship was also significant when the education level of the parents, the time of diagnosis and the age of the child were controlled for $(r=0.35$; $p<0.005)$. There was a positive correlation between the number of night time blood glucose measurements and the GAD-7 scores and a negative correlation with the age of the child. The perceived proficiency in glucagon administration of parents was negatively correlated with the PAGA scores.
Table 2 shows the correlation between the diabetes related variables and the scores in the questionnaires.

In further analysis, the parents were grouped into two sub-groups: those whose children had experienced loss of consciousness or seizures; and those whose children had not. The two groups did not differ in terms of $\mathrm{FoH}$, anxiety, misconceptions about glucagon administration, HbA1c levels, and day and night time measures (Table 3). There was no significant difference between the children using CGM and self-monitoring of blood glucose (SMBG) in terms of parental $\mathrm{FoH}$, anxiety and misconceptions about glucagon administration (Table 4). Furthermore, there was no significant difference between MDI and IIP users in terms of GAD-7 $(p=0.38)$ and FoH scores $(p=0.84)$.

\section{Discussion}

Mostly, the parents of children with T1D have concerns about hypoglycemia and its unfavorable short-term and long-term effects. Severe hypoglycemia can be safely treated with glucagon administration by the caregivers in a free setting. Nonetheless, families have difficulties in preparing, drawing the correct dose and administering it during a severe hypoglycemia episode, which, in turn, raises anxiety $(7,12)$. In the current study, parents evaluated their competence in glucagon administration as 6 out of 10 and $85 \%$ of them reported that they would administer glucagon immediately if there was a loss of consciousness.

\begin{tabular}{|c|c|c|c|c|c|c|c|c|c|}
\hline & $\begin{array}{l}\text { Age in } \\
\text { months }\end{array}$ & $\begin{array}{l}\text { Diabetes } \\
\text { duration }\end{array}$ & $\mathrm{HbA1c}$ & $\begin{array}{l}\text { Day time } \\
\text { glucose } \\
\text { measurement }\end{array}$ & $\begin{array}{l}\text { Nighttime } \\
\text { glucose } \\
\text { measurement }\end{array}$ & $\begin{array}{l}\text { Perceived } \\
\text { proficiency } \\
\text { in glucagon } \\
\text { administration }\end{array}$ & $\begin{array}{l}\text { PAGA } \\
\text { Score }\end{array}$ & $\begin{array}{l}\text { FoH } \\
\text { Score }\end{array}$ & $\begin{array}{l}\text { GAD-7 } \\
\text { Score }\end{array}$ \\
\hline Age in months & 1 & & & & & & & & \\
\hline $\begin{array}{l}\text { Diabetes } \\
\text { duration }\end{array}$ & $0.450 * *$ & 1 & & & & & & & \\
\hline $\mathrm{HbA1c}$ & $0.257^{*}$ & $0.432 * *$ & 1 & & & & & & \\
\hline $\begin{array}{l}\text { Day time } \\
\text { glucose } \\
\text { measurement }\end{array}$ & -0.217 & 0.054 & 0.087 & 1 & & & & & \\
\hline $\begin{array}{l}\text { Nighttime } \\
\text { glucose } \\
\text { measurement }\end{array}$ & $-0.375^{* *}$ & -0.029 & -0.182 & $0.306^{*}$ & 1 & & & & \\
\hline $\begin{array}{l}\text { Perceived } \\
\text { proficiency } \\
\text { in glucagon } \\
\text { administration }\end{array}$ & 0.016 & 0.08 & 0.031 & -0.012 & -0.016 & 1 & & & \\
\hline PAGA score & -0.186 & -0.067 & 0.159 & 0.077 & 0.068 & -0.541 * * & 1 & & \\
\hline FoH score & $-0.254^{*}$ & 0.045 & 0.121 & 0.140 & 0.088 & -0.042 & 0.211 & 1 & \\
\hline GAD-7 score & $-0.243^{*}$ & -0.134 & 0.099 & 0.169 & $0.241 *$ & -0.052 & $0.246^{*}$ & $0.395^{* *}$ & 1 \\
\hline
\end{tabular}




\begin{tabular}{|c|c|c|c|}
\hline & $\begin{array}{l}\text { Loss of consciousness/ } \\
\text { seizures }(n=16)\end{array}$ & $\begin{array}{l}\text { No loss of consciousness/ } \\
\text { seizures }(n=52)\end{array}$ & $\mathrm{p}$ value \\
\hline PAGA score & $12.9(0-25)$ & $13.4(0-30)$ & 0.644 \\
\hline FoH score & $49.8(27-81)$ & $34.9(21-91)$ & 0.449 \\
\hline GAD-7 score & $8.1(0-21)$ & $6.1(0-19)$ & 0.303 \\
\hline $\operatorname{HbA1c}(\%)$ & $7.7(5.7-12.3)$ & $7.6(5.5-14)$ & 0.569 \\
\hline Day-time glucose measurement ( $\geq 7$ times/day) ( $\%$ ) & 37.5 & 58 & 0.327 \\
\hline Night-time glucose measurement ( $\geq 7$ times/week) (\%) & 44 & 35 & 0.816 \\
\hline
\end{tabular}

Table 4. Continuous glucose monitoring and self-monitoring of blood glucose groups

\begin{tabular}{llll}
\hline & CGM group $(\mathrm{n}=39)$ & SMBG group $(\mathrm{n}=29)$ & $\mathrm{p}$ value \\
\hline PAGA score & $12.4(0-30)$ & $14.5(2-30)$ & 0.911 \\
FoH score & $46.9(20-85)$ & $47.6(21-91)$ & 0.961 \\
GAD-7 score & $6.5(0-20)$ & $6.8(0-21)$ & 0.413 \\
Child's age (years) & $8.7(2.7-17.2)$ & $10.5(2.8-17.5)$ & 0.598 \\
Diabetes duration (months) & $32.8(6-116)$ & $38.4(6-107)$ & 0.799 \\
\hline
\end{tabular}

PAGA: parental anxiety for glucagon administration, FoH: fear of hypoglycemia, GAD-7: generalized anxiety disorder-7, CGM: continuous glucose monitoring, SMBG: self-monitoring of blood glucose

These results indicate some parents have hesitations and regard themselves as incompetent when it comes to glucagon administration. Diabetes teams should emphasize the importance of glucagon administration in their training about managing severe hypoglycemia. Moreover, structured and practical education should be given to caregivers in order to lessen their anxiety and increase self-confidence. In our experience, as most families rarely need to use glucagon for severe hypoglycemia in any given year, it is likely they may forget the details of the administration in an acute emergency situation. Therefore, practical education about glucagon administration should be repeated annually (12).

Recently, nasal glucagon has been approved for treatment of severe hypoglycemia and has subsequently gained some popularity. It is ready to use, needle-free and involves a one-step administration compared to the other form. Pharmacodynamic studies support that intranasal glucagon had similar efficacy compared to intramuscular glucagon in the treatment of hypoglycemia in children and adolescents with T1D (13). Research reveals that caregivers and acquaintances administering intranasal glucagon have been able to administer it faster, more confidently and in accurate doses (14). Whereas intramuscular glucagon creates fear and anxiety (15), nasal glucagon seems an effective, user friendly and well tolerated method of treating hypoglycemia for caregivers in the home and school setting $(16,17)$. In the current study, some of the PAGA questions included physical difficulties concerning intramuscular glucagon administration such as "the needle will hurt because of the size". The parents stated that they had difficulty with these issues. They also reported a lack of confidence in glucagon administration. These results show that practical and simple administrations are needed for the correct use of glucagon. Expanding intranasal glucagon use could ease and strengthen the administration process before it becomes more serious (18) and would address an important unmet medical need (16). In turn, it may help to reduce parental concerns and pave the way for more effective use of glucagon. Although research into the psychosocial impact of intranasal glucagon is rare, caregivers stated it was less stressful to use compared to intramuscular glucagon (14). Therefore, in order to use nasal glucagon in all countries, an international initiative should be advanced under the leadership of the International Society for Pediatric and Adolescent Diabetes. Moreover, health systems of countries should reimburse nasal glucagon as it constitutes an emergency medicine.

Concerns about hypoglycemia may lead children with T1D and their parents to inject lower doses of insulin, over-eat or feed, limit their daily exercises and generally follow frequent blood glucose monitoring $(8,9)$. These interventions may cause undesirable elevations in blood glucose levels (19). Due to the fact that $75 \%$ of hypoglycemia in children is seen at night (20), some parents often wake up at night 
and measure blood glucose. This may cause anxiety in the children and parents (21). With increasing levels of anxiety, a decrease in quality of life and metabolic control and diabetes-related burnout can be seen in both parents and children $(8,20,22)$. It is also known that the prevalence of hypoglycemia and loss of consciousness or seizure as a result of hypoglycemia are associated with $\mathrm{FoH}$ among the parents $(8,19,23,24)$. The current study supports the literature in these aspects. In the validity and reliability study of the Turkish adaptation of GAD-7 scale, patients who were diagnosed with GAD-7 scored an average of 12.03 [standard deviation (SD) \pm 5.07 ] and the healthy control group scored 6.11 ( $\mathrm{SD} \pm 4.35)$ (11). The mean GAD-7 score of the participants $(6.6 \pm 5.4)$ suggested that the study group did not differ from the general population. It was found that the anxiety level of the parent was positively correlated with the frequency of glucose measurements during night time, $\mathrm{FoH}$ and misconceptions about glucagon administration. However, there was no association between HbA1c levels of the children and their parents' anxiety levels and FoH. Some research also reports that there was no direct association between $\mathrm{FoH}$ and $\mathrm{HbA1C}$ but an indirect association with parenting stress was reported (25).

The literature reveals both negative and positive psychological effects of CGM technologies in T1D treatment. Some research demonstrated that parental FoH and distress levels diminished with CGM use $(26,27)$. On the other hand, there are studies indicating no alleviation in FoH in CGM use compared to the control groups $(28,29)$. In the current study, we compared parental $\mathrm{FoH}$ and their anxiety levels when their children were CGM users compared to the parents of SMBG users. There was no significant difference between their anxiety level, FoH, and frequency of daily and nightly glucose measurements.

\section{Study Limitations}

There are certain limitations to the current study. First of all, the number of cases in the study was small. In further research, the number of participants could be increased and grouped according to CGM and, or only IIP and SMBG use. Another limitation was the lack of reliability and validity of the PAGA questionnaire used in the study. The PAGA questionnaire was generated by the study team because of the lack of a standardized measure regarding this issue. Further research may be needed to demonstrate that the PAGA questionnaire is a reliable measure to understand the misconceptions regarding glucagon administration of parents with T1D children. There is no doubt that when nasal glucagon is available in Turkey, it would be of value to include parental experiences regarding the use of nasal glucagon in a future study. Despite the limitations, we feel that this pilot study is valuable as it is the first study that has investigated the attitudes and misconceptions of the parents of children with T1D regarding intramuscular glucagon administration.

\section{Conclusion}

In conclusion, parents of children with T1D state their anxiety and fear associated with hypoglycemia and glucagon administration even without presence of prior experiences with severe hypoglycemia. Structured and practical training should be carried out to increase parents' self-confidence including annual refresher training for home glucagon administration. Moreover, the availability and widespread use of intranasal glucagon should be encouraged, as it will lead to a reduction in glucagon administration failure and parental anxiety, emergency department visits and hospital time for the parents.

\section{Acknowledgement}

The authors would like to thank all the participants and Alan J. Newson for the English language editing.

\section{Ethics}

Ethics Committee Approval: There was no ethical committee application for the current study. This work is a survey study.

Informed Consent: Consent form was filled out by all participants.

Peer-review: Externally peer-reviewed.

\section{Authorship Contributions}

Surgical and Medical Practices - Concept - Design - Data Collection or Processing - Analysis or Interpretation Literature Search - Writing: All authors.

Financial Disclosure: The authors declared that this study received no financial support.

\section{References}

1. Abraham MB, Jones TW, Naranjo D, Karges B, Oduwole A, Tauschmann M, M. Maahs D. ISPAD Clinical Practice Consensus Guidelines 2018: assessment and management of hypoglycemia in children and adolescents with diabetes. Pediatr Diabetes 2018;19:178-192.

2. Tomky D, Detection, prevention and treatment of hypoglycemia in the hospital. Diabetes Spectr 2005;18:39-44.

3. Barnard K, Thomas S, Royle P, Noyes K, Waugh N. Fear of hypoglycaemia in parents of young children with type 1 diabetes: a systematic review. BMC Pediatr 2010;10:50. 
4. Van Name MA, Hilliard ME, Boyle CT, Miller KM, DeSalvo DJ, Anderson BJ, Laffel LM, Woerner SE, DiMeglio LA, Tamborlane WV. Nighttime is the worst time: Parental fear of hypoglycemia in young children with type 1 diabetes. Pediatr Diabetes 2018;19:11 4-120. Epub 2017 Apr 21

5. Brown JB, Reichert SM, Valliere Y, Webster-Bogaert S, Ratzki-Leewing A, Ryan BL, Harris SB. Living With Hypoglycemia: an Exploration of Patients' Emotions: Qualitative Findings From the InHypo-DM Study, Canada. Diabetes Spectr 2019;32:270-276.

6. Pearson T. Glucagon as a treatment of severe hypoglycemia: safe and efficacious but underutilized. Diabetes Educ 2008;34:128-134.

7. Kedia N. Treatment of severe diabetic hypoglycemia with glucagon: an underutilized therapeutic approach. Diabetes, Metab Syndr Obes $201 ; 4: 337$

8. Gonder-Frederick LA, Fisher CD, Ritterband LM, Cox DJ, Hou L, DasGupta AA, Clarke WL. Predictors of fear of hypoglycemia in adolescents with type 1 diabetes and their parents. Pediatric Diabetes 2006;7:215-222.

9. Şen Celasin N, Çövener Özçelik Ç, Şahin Ş. Psychometric properties of the Turkish version of the University of Virginia parent low blood sugar survey. J Clin Res Pediatr Endocrinol 2018;10:162-167. Epub 2017 Aug 21

10. Spitzer RL, Kroenke K, Williams JB, Löwe B. A brief measure for assessing generalized anxiety disorder: the GAD-7. Arch Intern Med 2006;166:1092-1097.

11. Konkan R, Şenormanc Ö, Güçlü O, Aydın E, Sungur MZ. Yayğın anksiyete bozukluğu-7 (yab-7) testi türkçe uyarlaması, geçerlik ve güvenirliği. Arch Neuropsychiatry 2013;50:53-59.

12. Harrism G, Diment A, Sulway M, Wilkinson M. Glucagon administration-underevalued and undertaught. Pract Diabet Int 2001;18:22-25.

13. Sherr JL, Ruedy KJ, Foster NC, Piché CA, Dulude H, Rickels MR, Tamborlane WV, Bethin KE, DiMeglio LA, Fox LA, Wadwa RP, Schatz DA, Nathan BM, Marcovina SM, Rampakakis E, Meng L, Beck RW; T1D Exchange Intranasal Glucagon Investigators. Glucagon Nasal Powder: A Promising Alternative to Intramuscular Glucagon in Youth With Type 1 Diabetes. Diabetes Care 2016;39:555-562. Epub 2016 Feb 16

14. Yale JF, Dulude $H$, Egeth $M$, Piché CA, Lafontaine M, Carballo D, Margolies R, Dissinger E, Shames AR, Kaplowitz N, Zhang MX, Zhang $S$, Guzman CB. Faster use and fewer failures with needle-free nasal glucagon versus injectable glucagon in severe hypoglycemia rescue: a simulation study. Diabetes Technol Ther 2017;19:423-432. Epub 2017 May 30

15. Newswanger B, Prestrelski S, Andre AD. Human factors studies of a prefilled syringe with stable liquid glucagon in a simulated severe hypoglycemia rescue situation. Expert Opin Drug Deliv 201 9;16:10151025.

16. Pontiroli AE, Ceriani V. Intranasal glucagon for hypoglycaemia in diabetic patients. An old dream is becoming reality? Diabetes Obes Metab 2018;20:1812-1816. Epub 2018 May 2

17. Deeb LC, Dulude H, Guzman CB, Zhang S, Reiner BJ, Piché CA, Pradhan S, Zhang XM. A phase 3 multicenter, open-label, prospective study designed to evaluate the effectiveness and ease of use of nasal glucagon in the treatment of moderate and severe hypoglycemia in children and adolescents with type 1 diabetes in the home or school setting. Pediatr Diabetes 2018;19:1007-1013. Epub 2018 Mar 22.
18. Pontiroli AE, Tagliabue E. Therapeutic Use of Intranasal Glucagon: Resolution of Hypoglycemia. Int J Mol Sci 2019;20:3646.

19. Monaghan MC, Hilliard ME, Cogen FR, Streisand R. Nighttime caregiving behaviors among parents of young children with Type 1 diabetes: associations with illness characteristics and parent functioning. Fam Syst Health 2009;27:28-38.

20. Davis EA, Keating B, Byrne GC, Russell M, Jones TW. Hypoglycemia: incidence and clinical predictors in a large population-based sample of children and adolescents with IDDM. Diabetes Care 1997;20:2225.

21. Clarke W, Jones T, Rewers A, Dunger D, Klingensmith GJ. Assessment and management of hypoglycemia in children and adolescents with diabetes. Pediatr Diabetes 2009;10(Suppl 12):134-145. Erratum in: Pediatr Diabetes 2013;14:388-389

22. Johnson SR, Cooper MN, Davis EA, Jones TW. Hypoglycaemia, fear of hypoglycaemia and quality of life in children with Type 1 diabetes and their parents. Diabet Med 2013;30:1126-1131. Epub 2013 Jun 28

23. Patton SR, Dolan LM, Henry R, Powers SW. Parental fear of hypoglycemia: young children treated with continuous subcutaneous insulin infusion. Pediatr Diabetes 2007;8:362-368.

24. Patton SR, Dolan LM, Henry R, Powers SW. Fear of hypoglycemia in parents of young children with type 1 diabetes mellitus. J Clin Psychol Med Settings 2008;15:252-259. Epub 2008 Jul 26

25. Viaene AS, Van Daele T, Bleys D, Faust K, Massa GG. Fear of Hypoglycemia, Parenting Stress, and Metabolic Control for Children with Type 1 Diabetes and Their Parents. J Clin Psychol Med Settings 2017;24:74-81.

26. Juvenile Diabetes Research Foundation Continuous Glucose Monitoring Study Group, Beck RW, Lawrence JM, Laffel L, Wysocki T, Xing D, Huang ES, Ives B, Kollman C, Lee J, Ruedy KJ, Tamborlane WV. Quality-of-life measures in children and adults with type 1 diabetes: Juvenile Diabetes Research Foundation Continuous Glucose Monitoring randomized trial. Diabetes Care 2010;33:2175-2177. Epub 2009 Dec 2.

27. Juvenile Diabetes Research Foundation Continuous Glucose Monitoring Study Group, Beck RW, Lawrence JM, Laffel L, Wysocki T, Xing D, Huang ES, Ives B, Kollman C, Lee J, Ruedy KJ, Tamborlane WV. Quality-of-life measures in children and adults with type 1 diabetes: Juvenile Diabetes Research Foundation Continuous Glucose Monitoring randomized trial. Diabetes Care 2010;33:2175-2177. Epub 2010 Aug 9. Erratum in: Diabetes Care 2010;33:2725.

28. Mauras N, Beck R, Xing D, Ruedy K, Buckingham B, Tansey M, White $\mathrm{NH}$, Weinzimer SA, Tamborlane W, Kollman C; Diabetes Research in Children Network (DirecNet) Study Group. A randomized clinical trial to assess the efficacy and safety of real-time continuous glucose monitoring in the management of type 1 diabetes in young children aged 4 to < 10 years. Diabetes Care 2012;35:204-210. Epub 2011 Dec 30

29. Markowitz JT, Pratt K, Aggarwal J, Volkening LK, Laffel LM. Psychosocial correlates of continuous glucose monitoring use in youth and adults with type 1 diabetes and parents of youth. Diabetes Technol Ther 2012;14:523-526. Epub 2012 Apr 23 


\begin{tabular}{l}
\hline Appendix 1. Questionnaire evaluating parental anxiety for glucagon administration \\
\hline \multicolumn{3}{l}{ Below are some concerns about glucagon use. Please mark how much you are concerned about each item. } \\
\hline
\end{tabular}

